\title{
How to design and write a clinical research protocol in Cosmetic Dermatology
}

Como desenhar e escrever um protocolo de pesquisa clínica em Cosmiatria

\author{
Ediléia Bagatin ${ }^{1}$
}

Helio A. Miot $^{2}$

\begin{abstract}
Cosmetic Dermatology is a growing subspecialty. High-quality basic science studies have been published; however, few double-blind, randomized controlled clinical trials, which are the major instrument for evidence-based medicine, have been conducted in this area. Clinical research is essential for the discovery of new knowledge, improvement of scientific basis, resolution of challenges, and good clinical practice. Some basic principles for a successful researcher include interest, availability, persistence, and honesty. It is essential to learn how to write a protocol research and to know the international and national regulatory rules. A complete clinical trial protocol should include question, background, objectives, methodology (design, variable description, sample size, randomization, inclusion and exclusion criteria, intervention, efficacy and safety measures, and statistical analysis), consent form, clinical research form, and references. Institutional ethical review board approval and financial support disclosure are necessary. Publication of positive or negative results should be an authors' commitment.

Keywords: Clinical protocols; Clinical trial; Comparative study; Cosmetics; Epidemiologic research design; Research design

Resumo: Cosmiatria é uma sub-especialidade em grande crescimento. Estudos em ciência básica de alta qualidade têm sido publicados; ao contrário, existem poucos estudos clínicos duplo-cegos, randomizados e controlados, que constituem o maior instrumento para medicina baseada em evidência nessa área. A pesquisa clínica é essencial para a descoberta de novos conhecimentos, melhora das bases científicas, solução de desafios e boa prática clínica. Para ser um pesquisador bem sucedido, os princípios básicos são interesse, disponibilidade, persistência e honestidade. É essencial aprender como escrever um protocolo de pesquisa e conhecer as regras regulatórias nacionais e internacionais. Um protocolo de pesquisa clínica completo deve incluir questão, fundamentos, objetivos, metodologia (desenho, descrição das variáveis, tamanho da amostra, randomização, critérios de inclusão e exclusão, intervenção, parâmetros de eficácia e segurança e análise estatística), termo de consentimento livre e esclarecido, ficha clínica e referências. A aprovação do Comitê de Ética em Pesquisa e a declaração do financiamento são imprescindíveis. A publicação de resultados positivos ou negativos deve ser um comprometimento dos autores.

Palavras-chave: Cosméticos; Ensaio clínico; Estudo comparativo; Projetos de pesquisa; Projetos de pesquisa epidemiológica; Protocolos clínicos
\end{abstract}

Received on 09.04.2012.

Approved by the Advisory Board and accepted for publication on 15.05.2012.

* Work conducted at the Department of Dermatology - Sao Paulo-state School of Medicine - Federal University of Sao Paulo (EPM-UNIFESP) and School of Medicine of Botucatu - Universidade Estadual Paulista "Julio de Mesquita Filho" (FMB-UNESP) - Botucatu (SP), Brazil.

Financial Support: None

Conflict of Interest: None

PhD - Professor, Federal University of Sao Paulo (Universidade Federal de Sao Paulo - UNIFESP) - Sao Paulo (SP), Brazil

PhD - Assistant professor, Departament of Dermatology and Radiotherapy, Universidade Estadual Paulista "Julio de Mesquita Filho" (UNESP) - Botucatu (SP), Brazil.

(C)2013 by Anais Brasileiros de Dermatologia 


\section{INTRODUCTION}

Cosmetic Dermatology is a very exciting subspecialty of increasing interest among dermatologists, researchers, pharmaceutical companies, and the general public. Nevertheless, the greatest number of studies in the medical literature with high methodological quality refers to basic and experimental science and not to clinical studies, which limits generalization of results in clinical practice.

Since cosmetic complaints are due to known physiopathological processes, classical epidemiological approaches are suitable to assess cosmetic endpoints. ${ }^{1,2}$ Randomized controlled clinical trials are the best for determining intervention efficacy in specific situations and are the major instrument for evidencebased medicine. ${ }^{3}$ It is necessary to accumulate good trials to get solid evidence for better clinical practice. ${ }^{4}$

There is urgency for well designed clinical trials followed by consistent publications in accordance with the CONSORT (Consolidation of Standards for Reporting Trials) Statement and the principles of GCP (Good Clinical Practice) regarding cosmetic dermatology. Brazilian researchers should also know the guidelines of the Good Clinical Practice: Document of the Americas (Boas Práticas Clínicas: Documento das Américas - Portuguese) and the regulatory rules of the Brazilian National Health Surveillance Agency (Agência Nacional de Vigilância Sanitária - ANVISA Portuguese). ${ }^{6}$

Information technology has become cheaper, widely accessible and easy to use, playing an important role in the appropriate management of patients. On the other hand, it is essential that clinical trials be critically evaluated and that their limitations be properly understood. If they are improperly designed, their performance becomes unethical, as subjects may be submitted to misguided investigation and interventions, and the results will be meaningless or even erroneous.

The main research aims should be discovering and interpreting new knowledge, exploring subgroups, improving scientific basis, or resolving challenges in clinical practice. Outcomes are expected to confirm, modify, or reject existing knowledge or the efficacy of a therapy or cosmetic procedure. Organized, good-quality research should remain meaningful for a long time and may give rise to new investigations. It also offers opportunity for international collaboration and visibility as well as to get funding sources. Research may influence health system policies and bring benefits to doctors, patients, and the general population. ${ }^{7}$

Investigators' first step is to define a study line or area of interest. Secondly, it is essential to study extensively before elaborating the content of a research protocol. The basic principles for success are interest, availability, persistence, and honesty.
Concerning scientific research, there is no place for fraud. It may not be able to prove or disprove hypotheses, but it always improves knowledge regarding the protocol. ${ }^{8,9}$ Involvement of professionals from various specialties can gather specific expertise and improve research quality. ${ }^{10}$

A beginner in research will be faced with the task of writing a clinical trial protocol which should comprise the topics described below (some examples are included) and in chart $1 .{ }^{11-15}$

\section{HYPOTHESIS OR QUESTION}

The hypothesis or question should be original, simple, and logic. The "FINER" criteria - which means feasible, interesting, novel, ethical, and relevant - must be considered. It rises from previous studies in the researcher's area of interest, relevant discussion on scientific events, literature search, curiosity, or innovative mind.

Example: Is oral isotretinoin effective, safe, and superior to sunscreen plus moisturizer in the treatment of photoaging?

\section{INTRODUCTION AND BACKGROUND}

An extensive and critical review of the literature is essential to find out some gaps or if another investigator has already studied the same matter. Discussion and feedback from seniors and experts are also helpful. After that, the researcher may maintain, improve, or reject the initial question. Based on a definitive hypothesis, the introduction and background might be written. This section should be concise and strictly related to the subject of investigation and to the questions to be answered.

\section{OBJECTIVES}

The study may comprise just one general objective or primary and secondary objectives.

Example:

Primary objective: to evaluate the efficacy and safety of oral isotretinoin as compared to sunscreen plus moisturizer in the treatment of photoaging.

Secondary objective: to evaluate the impact of treatments on quality of life.

\section{METHODOLOGY}

It is the most important part for conducting good-quality research and obtaining valid inferences. A complete protocol involving human beings should include design, precise definition of the disease/endpoint, clear description of variables, well-defined inclusion and exclusion criteria, efficacy and safety parameters, sample size calculation and randomization, statistical analysis plan, detailed description of 
CHART 1: Schematic structure of a clinical research protocol

\begin{tabular}{|c|c|c|}
\hline & Topic & Example \\
\hline 1 & Idea / Hypothesis & Oral isotretinoin can reduce the incidence of actinic keratosis. \\
\hline 2 & Bibliographic research & Background and reason for the study \\
\hline 3 & Study design & $\begin{array}{l}\text { Double-blind, randomized, placebo-controlled, longitudinal study: } \\
\text { Group A: Sunscreen + oral isotretinoin. } \\
\text { Group B: Sunscreen + oral placebo. } \\
\text { Two months of follow-up after cryotherapy (5-second spray of liquid } \\
\text { nitrogen) of all actinic keratoses. }\end{array}$ \\
\hline 4 & Diagnosis conception & $\begin{array}{l}\text { Actinic keratosis will be defined after clinical evaluation by a boarded } \\
\text { dermatologist, not by histopathological analysis, which makes } \\
\text { subsequent lesion counting impracticable. }\end{array}$ \\
\hline 5 & Definition of variables & $\begin{array}{l}\text { Dependent: Counting actinic keratoses in a standard area; histological } \\
\text { expression of proliferative (Ki-67) and apoptotic factors (p53 and Bcl-2) } \\
\text { Independent: Treatment group. } \\
\text { Potential confounders: Age, skin phototype, sun exposure. }\end{array}$ \\
\hline 6 & Inclusion / Exclusion criteria & $\begin{array}{l}\text { Immunocompetent patients older than } 50 \text { years, both genders, with } \\
\text { up to } 30 \text { actinic keratoses on the face and forearms. } \\
\text { Those randomized to isotretinoin should be normolipemic and } \\
\text { present normal liver function. }\end{array}$ \\
\hline 7 & Sampling & $\begin{array}{l}\text { Random sample selection of } 50 \text { patients based on an expected } \\
\text { reduction of up to } 30 \% \text { in the incidence of actinic keratoses, power of } \\
80 \% \text {, and alpha } 5 \% .\end{array}$ \\
\hline 8 & Statistical analysis & Generalized linear mixed model (negative binomial) \\
\hline 9 & Chronogram and budget & $\begin{array}{l}\text { Time allocated for each phase (table), and calculation of each } \\
\text { predictable expense. }\end{array}$ \\
\hline 10 & $\begin{array}{l}\text { Ethics committee approval / } \\
\text { Funding / Clinical trial registration }\end{array}$ & $\begin{array}{l}\text { Study approved by institutional research ethics committee, financially } \\
\text { supported by CNPq and registered at www.ensaiosclinicos.gov.br }\end{array}$ \\
\hline 11 & Criteria for discontinuation & Severe adverse effects should lead to study discontinuation \\
\hline
\end{tabular}

interventions, a chronogram of activities, consent form, clinical research form (CRF), and references.

Endpoint characterization and precise variable description are mandatory and should express the main definitions of each variable in the study, how they will be obtained, presuppositions, techniques, and instruments. ${ }^{16}$

Early statistical consultation is essential to determine sample size, standardize variables, and plan data analysis and future data presentation. ${ }^{17,18}$

In summary, the researcher should clearly state the "PICO" elements (patient, intervention, comparison, and outcome) in this section.

\section{DESIGN}

There are many study designs; clinical trials follow the interventional design.

\section{Interventional}

The study population is submitted to clinical or surgical therapies or procedures. Therapeutic trials may be designed as the following: placebo-controlled, compared to standard treatment; randomized, not randomized; double-blind, single-blind, open; parallel, cross-over, or cluster allocation. The gold standard design is parallel-group, double-blind, randomized, and controlled with the standard therapy. This is usually referred to as RCT (randomized controlled trial). ${ }^{19}$ Open studies and those with associated interventions in just one group of subjects can report positive con- 
CHART 2: The most common statistical tests for bivariate data analysis (unpaired data) according to dependent and independent variables

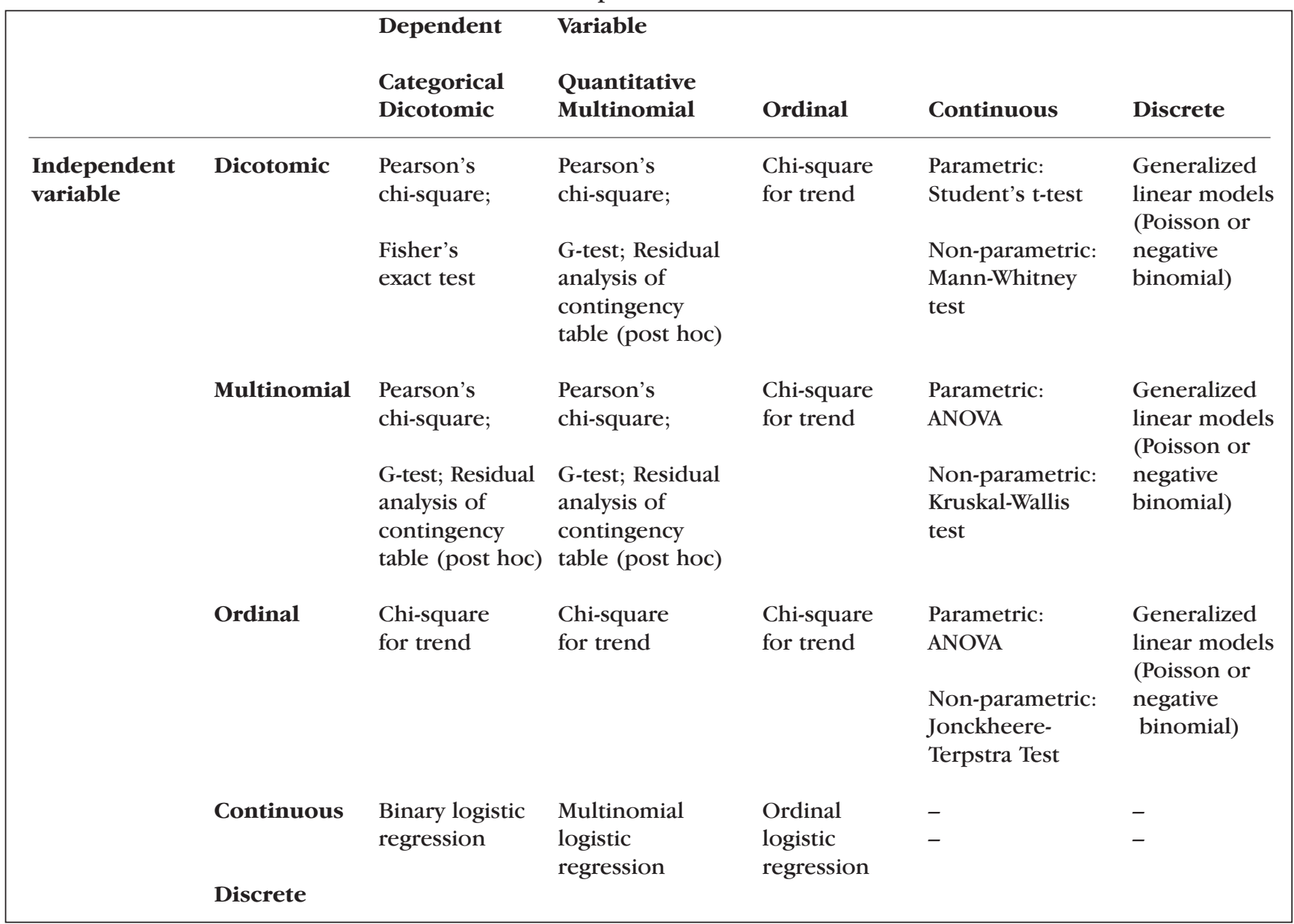

clusions, but they have limited value for Evidencebased medicine..$^{20,21}$

\section{Observational}

- Cohort - prospective, historical: a population exposed to the condition under investigation is followed along time and evaluated in determined periods of time.

- Case-control - retrospective: two populations that were or are exposed to a condition are compared in relation to the presence or absence of an outcome under investigation.

- Transversal or cross-sectional: it is a prevalence study; the whole population is analyzed in just one period of time.

- Epidemiological description - case series: it summarizes the characteristics of a population.

- Descriptive: it reports personal experiences

- Experimental

- Example: an interventional, randomized, comparative (parallel groups), prospective, and evaluator-blind clinical trial including 32 healthy women, aged from 40 to 55 years, to evaluate efficacy and safe- ty of oral isotretinoin $(20 \mathrm{mg} /$ day, three times a week, associated with sunscreen plus moisturizer, 22 women) versus the use of sunscreen plus moisturizer (10 women) during three months in the treatment of photoaging.

\section{SAMPLE SIZE CALCULATION, SUBJECT ALLOCATION, AND RANDOMIZATION}

There are many formulas to calculate sample size, and randomization lists are available on the Internet. Sample size calculation is inversely proportional to the minimal clinically significant difference between groups and tolerable error of estimation. These parameters should be determined by the investigators and previously discussed with the statistician. ${ }^{22,23}$

Studies with few subjects may not allow us to detect differences. On the other hand, an excess of subjects may be unnecessarily exposed to investigation, leading to clinically meaningless conclusions. Both are unethical situations. ${ }^{24}$

Subjects should come from the same population, especially if cultural, ethnical and socioeconomic aspects can interfere with the disease or treatment. Age 
ChART 3: The most common statistical tests to bivariate data analysis (paired data) according to dependent and independent variables

\begin{tabular}{|c|c|c|c|c|c|c|}
\hline \multirow{2}{*}{$\begin{array}{l}\text { Independent } \\
\text { variable }\end{array}$} & & \multicolumn{5}{|c|}{ Dependent Variable } \\
\hline & & $\begin{array}{l}\text { Categorical } \\
\text { Dicotomic }\end{array}$ & $\begin{array}{l}\text { Quantitative } \\
\text { Multinomial }\end{array}$ & Ordinal & Continuous & Discrete \\
\hline & Dicotomic & McNemar's test & $\begin{array}{l}\text { Generalized } \\
\text { mixed models } \\
\text { (multinomial) }\end{array}$ & $\begin{array}{l}\text { Generalized } \\
\text { mixed models } \\
\text { (ordinal data) }\end{array}$ & $\begin{array}{l}\text { Parametric: } \\
\text { Student's t-test } \\
\text { for paired data } \\
\text { Non-parametric: } \\
\text { Wilcoxon test }\end{array}$ & $\begin{array}{l}\text { Generalized } \\
\text { mixed models } \\
\text { (Poisson or } \\
\text { negative } \\
\text { binomial) }\end{array}$ \\
\hline & Multinomial & $\begin{array}{l}\text { Generalized } \\
\text { mixed models } \\
\text { (categorical } \\
\text { data) }\end{array}$ & $\begin{array}{l}\text { Generalized } \\
\text { mixed models } \\
\text { (categorical } \\
\text { data) }\end{array}$ & $\begin{array}{l}\text { Generalized } \\
\text { mixed models } \\
\text { (categorical } \\
\text { data) }\end{array}$ & $\begin{array}{l}\text { Parametric: } \\
\text { ANOVA for } \\
\text { repeated } \\
\text { measures } \\
\text { Non-parametric: } \\
\text { Friedman test }\end{array}$ & $\begin{array}{l}\text { Generalized } \\
\text { mixed models } \\
\text { (Poisson or } \\
\text { negative } \\
\text { binomial) }\end{array}$ \\
\hline & Ordinal & $\begin{array}{l}\text { Generalized } \\
\text { mixed models } \\
\text { (categorical } \\
\text { data) }\end{array}$ & $\begin{array}{l}\text { Generalized } \\
\text { mixed models } \\
\text { (categorical } \\
\text { data) }\end{array}$ & $\begin{array}{l}\text { Generalized } \\
\text { mixed models } \\
\text { (categorical } \\
\text { data) }\end{array}$ & $\begin{array}{l}\text { Generalized } \\
\text { mixed models }\end{array}$ & $\begin{array}{l}\text { Generalized } \\
\text { mixed models } \\
\text { (Poisson or } \\
\text { negative } \\
\text { binomial) }\end{array}$ \\
\hline & Continuous & $\begin{array}{l}\text { Generalized } \\
\text { mixed models } \\
\text { (categorical } \\
\text { data) }\end{array}$ & $\begin{array}{l}\text { Generalized } \\
\text { mixed models } \\
\text { (categorical } \\
\text { data) }\end{array}$ & $\begin{array}{l}\text { Generalized } \\
\text { mixed models } \\
\text { (categorical } \\
\text { data) }\end{array}$ & $\begin{array}{l}\text { Parametric: Pears } \\
\text { correlation coeffi } \\
\text { Non-parametric: } \\
\text { correlation coeffi }\end{array}$ & $\begin{array}{l}\text { n's } \\
\text { ent } \\
\text { pearman's } \\
\text { ent }\end{array}$ \\
\hline
\end{tabular}

and gender are classical restrictions in homogenizing group responses. Therefore, they should be allocated in a way that each participant has the same chance of being assigned to each group. Non-random subject allocation forms should be discouraged. These forms include casual (convenience-based), snowball, voluntary response, by saturation, and quota sampling. Randomization should eliminate selection bias, create comparable groups, and lend validity to statistical analysis. ${ }^{25}$

Finally, matching observations (e.g. longitudinal studies, pairing or side-by-side comparisons) require smaller samples, reduce estimation errors, and increase internal comparability among subjects. Longitudinal studies need a long-term follow-up to be useful for clinical practice. Immediate results alone may not demonstrate the real efficacy of the intervention.

\section{EFFICACY AND SAFETY MEASURES}

They should be objective and quantitative, as much as possible, and based on the state-of-the-art knowledge about the condition under investigation. It is highly recommended that the same phenomenon be assessed at different endpoints. ${ }^{21}$ Correlation between the results of each endpoint reinforces the trustworthiness of the effect. Confounders should be carefully considered and also assessed for later adjustment of their effects.

Example:

For results of photoaging treatment: patients' opinion, blind photographic evaluation, non-invasive measures (elasticity, skin surface, hydration, etc), clinical and histological images with quantitative digital analysis.

For adverse events related to oral isotretinoin: report of mucocutaneous or rare side effects, laboratorial tests (liver function, lipid profile, blood count).

\section{STATISTICAL ANALYSIS}

It is essential to find real correlations and trends which may or may not be significant and which may or may not imply causation. Every researcher, and even medical practitioners, should have some knowledge of statistical methods and analysis in order to choose the best study design and to interpret data. ${ }^{14}$

The study population should be analyzed as intention-to-treat (ITT), modified ITT and per-proto- 
col (PP). ${ }^{26}$ ITT population includes all subjects who used the treatment once or for a period of time and dropped out, whereas PP includes only those who completed the study.

Statistical significance is usually set as a two tailed p-value $<0.05$, which means that researchers accept the result of the probability related to the statistical test of less than 5\% for conclude that groups are diferent. Although $\mathrm{p}>0.05$ means insufficient evidence to demonstrate difference, it is not the same as no difference between groups. ${ }^{26}$

Data structure depends on the characteristics of the variables. Categorical or qualitative variables can be dichotomic (e.g. unhealthy/healthy, male/female), multinomial (e.g. homosexual/bisexual/heterosexual), or ordinal (e.g. Fitzpatrick's phototypes I-IV, Glogau's classification I-III) and should be represented by the percentile of each category. Quantitative variables always have a proportional scale among the values and can be continuous (e.g. age, weigh, height, disease length) or discrete (e.g. counting of cigarettes, number of sunburns). Quantitative data should be tested for normality with the Shapiro-Wilk test. If the distribution is parametric (normal), data should be represented by mean and standard deviation; if not, usually median and interquartile range can be used. ${ }^{27}$

The choice of which statistical test to use should take into account the nature of the dependent and independent variables, normality of data, and matching. According to these presuppositions, the main tests used are described in charts 2 and 3 .

Inter-rater concordance can be assessed using Cohen's (weighed) kappa for $2 \times 2$ assessments and using intraclass correlation coefficient (for complete agreement) for 2 or more raters. ${ }^{28}$ Adjustment of results by confounders is important to explore data, and multivariable analysis is frequently used for that purpose. The selection of co-variables to compound the final model is a debatable subject and is beyond the scope of this text. ${ }^{29}$

Unpaired data are usually analyzed by multiple logistic regression (categorical dependent variable) or generalized linear models (quantitative dependent variable). Paired data are usually analyzed by generalized mixed models. ${ }^{27}$

The consent form should be written in simple and popular language. The objective of the study, potential risks, benefits, and detailed procedures should be clearly described. The main researcher's contact should be displayed in case the participants have doubts or want to remove their consent, for instance. $^{30}$
Chronogram and budget should determine how long each phase of the study will last, calculate each predictable expense, and determine time for disbursement.

The complete protocol should be submitted to the Ethics Committee or Institutional Review Board (IRB). In Brazil, appreciation of the National Council on Ethics in Research (Conselbo Nacional de Etica em Pesquisa - CONEP - Portuguese) is required in some situations, such as new drug, multicentric and international studies, and research involving native indigenous population, children, and pregnant women.

After ethical approval, financial support may be obtained from governmental foundations, institutes, or pharmaceutical companies. Financial conflicts are minimized by author disclosure and clinical trial registry. Multicentric sponsored studies demonstrate high methodological quality, include a larger sample size, and are more likely to report meaningful results. ${ }^{15,31}$ The ideal situation should be a partnership between university, government, and industry to minimize financial interests in the results.

Afterwards, the study should be added to any online clinical trial record, such as www.clinicaltrials.gov or www.ensaiosclinicos.gov.br. These registers follow a strict process of validation, and a register number is usually requested by medical journals for publication.

At the end of the protocol, authors should inform any potential limitations of the study, drawbacks, and restrictions to generalization of the results. Clear awareness of the study limits strengthens the implications of the conclusions. ${ }^{32}$

Attempting to visualize possible final results (using charts and plots) is a useful exercise that allows revising the study structure and data analysis.

Sharing positive or negative results in scientific events as well as their publication are the authors' obligation. ${ }^{33}$ Good papers should also follow CONSORT standards, present the question and objectives, state how the sample size was determined, state if confounding factors were considered, and inform which randomization method was used. Statistical tests should be appropriate, interpretation of results and conclusions should be correlated with the initial hypothesis, and possible bias and applicability of findings should be reported.

High impact factor (IF) journals are preferable, as they increase the chance of paper access and citation. Discussions about the real importance of journal IF for clinical practice have been raised in the literature in recent years. ${ }^{34}$

In conclusion, to be a good researcher and writer, it is essential to read, study, think, and reflect, i.e., to exercise the brain every day. $\square$ 


\section{REFERENCES}

1. Noordzij M, Dekker FW, Zoccali C, Jager KJ. Study designs in clinical research. Nephron Clin Pract. 2009;113:c218-21.

2. Hennekens $\mathrm{CH}$, Buring JE. Epidemiology in medicine. Boston: Little, Brown and Co.; 1987.

3. Rees J. The nature of clinical evidence: floating currencies rather than gold standards. J Invest Dermatol. 2007;127:499-500.

4. Bigby M. Evidence-based medicine in a nutshell. A guide to finding and using the best evidence in caring for patients. Arch Dermatol 1998;134:1609-18.

5. Consort-statement.org [Internet]. Consort Transparent Reporting of Trials. Consolidation of standards for reporting trials. [cited 2011 Dec 22]. Available from: http://www.consort-statement.org

6. Portal.anvisa.gov [Internet]. Proteção à Saúde. Medicamentos. Assuntos de Interesse. Pesquisa Clínica [acesso 29 nov 2011]. Disponível em: http://portal.anvisa.gov.br.

7. Qureshi Al, Hutson AD, Harbaugh RE, Stieg PE, Hopkins LN; North American Trial of Unruptured and Ruptured Aneurysms Planning Committee. Methods and design considerations for randomized clinical trials evaluating surgical or endovascular treatments for cerebrovascular diseases. Neurosurgery. 2004;54:248-64.

8. Hulley S, Cummings S, Browner W, Grady D, Hearst N, Newman T. Designing clinical research: an epidemiologic approach. San Francisco: Lippincott; 2001

9. Fletcher RH, Fletcher SW. Clinical epidemiology: the essentials. 4 ed. São Francisco: Lippincott; 2005.

10. Carson PA. Clinical research in dermatology: 10 steps to getting started. Dermatol Ther. 2006;19:377-82.

11. Adetugbo K, Williams H. How well are randomized controlled trials reported in the dermatology literature. Arch Dermatol. 2000;136:381-5.

12. Singh G, Kaur V. Formulation of a research project. Indian J Dermatol Venereol Leprol. 2007;73:273-6.

13. García-Doval I, Naldi L. Introduction to clinical research in Dermatology: the link between clinical practice and research. Actas Dermosifiliogr. 2009;100:749-55.

14. Gilmore SJ. Evaluating statistics in clinical trials: Making the unintelligible intelligible. Austr J Dermatol. 2008;49:177-84.

15. Goldsmith LA. Conflict of interest and the JID. J Invest Dermatol. 2006;126:2147-8.

16. Silverman R, Kwiatkowski T. Research fundamentals: III. elements of a research protocol for clinical trials. Acad Emerg Med. 1998;5:1218-23.

17. Coutinho ESF, da Cunha GM. Conceitos básicos de epidemiologia e estatística para a leitura de ensaios clínicos controlados. Rev Bras Psiquiatr. 2005;27:146-51.

18. Alosh M, Fritsch K, Soukup M, Wilkin J. Clinical trials and statistical analyses: what should dermatologists look for in a report? Dermatol Ther. 2009;22:199-203.

19. Appel LJ. A primer on the design, conduct, and interpretation of clinical trials. Clin J Am Soc Nephrol. 2006;1:1360-7.

20. Hernandez-Perez E, Khawaja HA, Alvarez TYM. Oral isotretinoin as part of the treatment of cutaneous aging. Dermatol Surg. 2000;26:649-52.

21. Costa A, Lindmark L, Arruda LH, Assumpção EC, Ota FS, Pereira Mde 0, et al. Clinical, biometric and ultrasound assessment of the effects of daily use of a nutraceutical composed of lycopene, acerola extract, grape seed extract and Biomarine Complex in photoaged human skin. An Bras Dermatol. 2012;87:52-61.
22. Miot HA. Tamanho da amostra em estudos clínicos e experimentais. J Vasc Bras. 2011;10:276-8

23. Wittes J. Sample size calculations for randomized controlled trials. Epidemiol Rev 2002;24:39-53.

24. Williams $\mathrm{HC}$, Seed $\mathrm{P}$. Inadequate size of 'negative' clinical trials in dermatology. $\mathrm{Br}$ J Dermatol. 1993;128:317-26.

25. Berger VW. A review of methods for ensuring the comparability of comparison groups in randomized clinical trials. Rev Recent Clin Trials. 2006;1:81-6.

26. DeMets DL. Statistical issues in interpreting clinical trials. J Intern Med. 2004 255:529-37.

27. Norman GR, Streiner DL. Biostatistics. The bare essentials. 3rd ed. Shelton, Connecticut: People's Medical Publishing House; 2008.

28. Sim J, Wright CC. The kappa statistic in reliability studies: use, interpretation, and sample size requirements. Physical therapy. 2005;85:257-68.

29. Katz MH. Multivariable analysis. A practical guide for clinicians. 2nd ed Cambridge, UK: Cambridge University Press; 2006.

30. Dimond B. Dermatology: obtaining a patient consent in clinical trials. Br J Nurs 2006;15:500-1.

31. Perlis CS, Harwood M, Perlis RH. Extent and impact of industry sponsorship conflicts of interest in dermatology research. J Am Acad Dermatol. 2005;52:967-71.

32. Hartrick CT. Quality assessment in clinical trials: considerations for outcomes research in interventional pain medicine. Pain Pract. 2008;8:433-8.

33. Bagatin E, Parada MOB, Miot HA, Hassun KM, Michalany NS, Talarico S. A randomized and controlled trial about the use of oral isotretinoin for photoaging. Int $J$ Dermatol 2010;49:207-14.

34. Bagatin E, Gontijo B. The expansion of a measure: what is a scientific journa impact factor and how important is it for academic Brazilian dermatologists. Int $J$ Dermatol. 2011:50:1432-4.

How to cite this article: Bagatin E, Miot HA. How to design and write a clinical research protocol in Cosmetic Dermatology. An Bras Dermatol. 2013;88(1):69-75. 